\title{
The Future of Information Work: Designing Library and Information Courses for the Digital Age
}

\begin{abstract}
For over 100 years colleges of higher and further education have played important roles in the education of library and information professionals. However, the last decade has seen some significant changes in both the structure of teaching departments and the types of courses they deliver. This paper, delivered by Martin De Saulles at the $39^{\text {th }}$ Annual BIALL Conference held in Dublin in June 2008, outlines some of the pressures currently facing the library and information profession and describes how teaching departments have responded in terms of course developments.
\end{abstract}

Keywords: library schools; information work; courses

\section{Introduction}

Just as the library and information profession is going through significant changes, so too are the university departments which deliver courses in this area. Information and communication technologies, particularly the internet, have been responsible for many of these changes and information professionals require a broader range of technical skills than was often the case in the past. The challenge for those delivering courses at both undergraduate and postgraduate level is to incorporate these new requirements into the curriculum, without neglecting some of the core skills in the areas of information literacy and collection management. The following paragraphs will attempt to explore in more detail some of these issues and explain how, at the University of Brighton, we have been adapting to the digital information age.

\section{Current teaching of library and information courses}

There are currently 17 universities in the United Kingdom that teach library and information courses, split between 52 postgraduate and 10 undergraduate awards. Two of the dominant trends amongst these institutions over the previous 10 to 15 years has been a merging of library and information departments with other university departments, often computing, and a closing down of undergraduate courses. Driving these changes has been a combination of falling student numbers and increasing pressure from university management for greater operating efficiencies. In some cases, universities have stopped teaching in this area altogether. The University of Central England stopped enrolling new students to its courses in 2005.

\section{Reasons for decline in student numbers}

My institution, the University of Brighton, has not been immune to these pressures and we stopped enrolling new students on our two undergraduate awards in 2007. In our case, the ever decreasing numbers of applicants meant it was not viable to run these courses. This was a very difficult decision, as we have been teaching library and information courses since 1947 through our predecessor technical colleges. However, we decided instead to focus our efforts on our successful postgraduate courses which have a record of recruiting well. These developments lead to the question of why taught undergraduate courses in this subject area were not recruiting well, particularly as total undergraduate student numbers have been steadily increasing in recent years. I suspect there are several key reasons for this:

- The library profession has an image problem amongst young people with many of them attracted to the plethora of more "sexy" vocational courses, such as tourism management, media production or public relations. Fifteen years ago most of these courses did not exist and the options for course selection for 18 year olds was far less; 
- Pay rates for new graduate library and information professionals in much of the public sector are very low and the introduction of increased student fees has made it more difficult to pay off student loans;

- Qualification inflation means that more employers are demanding postgraduate qualifications for entry positions. This often means a first degree in a specific subject area and a postgraduate degree in library and information studies;

- Employees are finding it increasingly difficult to secure funding from their employers, as well as taking time off for undertaking courses on a part-time basis. Distance learning courses, such as those offered by Aberystwyth, have succeeded in attracting students who would, in previous years, have taken a course at a local college or university.

\section{Situation at University of Brighton}

At the same time as deciding to wind down our undergraduate courses, we decided to take another look at our postgraduate courses to make sure they were still relevant to the needs of the library and information profession. At the time we offered three courses:

- MA Information Studies - aimed at graduates wishing to start a career in the profession. The course comprised of a set of core modules that provided students with the essential skills required to take up a first professional post;

- MA Information Management - designed for current information professionals with at least several years experience who want to extend and update their skills;

- MA Health Informatics - aimed at library and information professionals working in the health sector and wishing to develop their skills.

The MA Information Studies course has been consistently successful at recruiting students with a regular intake of 20 to 30 new students a year. After a consultation with ex-graduates and employers, we decided to maintain the course in its current state, working to the maxim that if it's not broke don't fix it. However, the other two courses had seen a drop in student numbers in recent years and, following a consultation with a number of library and information professionals both in the UK and abroad, we decided that elements of these courses required altering. The key changes that we felt were necessary centred around the technological changes that were, and are still, taking place in the profession. It is no news to anyone working with information that the ubiquity of the personal computer and the internet are fundamentally changing the ways people, not just information professionals, find, consume and use information.
Whilst our two post-experience courses described above incorporated elements of this technological revolution, we realised that, even over the previous five years, changes in the way information is managed required us to make substantial changes to those courses.

\section{Design of new courses}

One of the key findings from our consultation exercise was that library and information professionals were aware of the technical changes taking place around them, but wanted a course that would help them understand these changes and be able to apply this understanding within the context of their work. Most of our students on the MA Information Management and MA Health Informatics courses were part-time and worked in a range of information roles. This range of roles also played a part in the redesign of the courses, as we were seeing fewer students from the more traditional public and academic library roles and more from a broader cross-section of the information profession. Many of these roles involved more technical responsibilities, such as intranet and database management, as well as the design and management of content management systems. It was becoming clear that showing students how to construct a basic web site using HTML was no longer sufficient. Understanding content management platforms such as Sharepoint, Drupal and Wordpress was of more relevance, as database driven sites were beginning to take over from the flat HTML structures which dominated the early days of the web.

As a consequence of this understanding we increased the number of elective options available to students with new modules in Information Architecture for the Web, Innovations in Online Information, Managing Knowledge and Collection Development in the Digital Age. We also changed the status of the awards from MA to MSc, reflecting the technical additions to the courses. Finally, we have responded to a recurring theme from our consultation which was to make the courses more workfriendly. Most of our students hold down full-time jobs while studying part-time, and juggling these roles along with family commitments is often very difficult. Consequently, the attendance for the modules on these new MSc courses takes place over 3 consecutive days which most students find easier than having to do modules that are spread out over the year. The new courses were launched in 2007 and the response from applicants has so far been very positive.

\section{Challenges and opportunities in the future of information work}

The above is an explanation of how we, at the University of Brighton, have responded to the changes taking place in the library and information profession, largely driven by new technologies and increasing work pressures. How 
successful these changes will be remains to be seen. We see course development as an iterative process of engagement with employers and potential students to understand their needs, as well as using our understanding of technical change and innovation to anticipate where our profession may be going in the future. The remainder of this paper will present a personal view, based on my experience as an academic and a practitioner, of some of the key challenges and opportunities I see in terms of the future of information work.

Over the previous 40 or so years there has been a fairly steady flow of literature, from academics and practitioners, on the state of the library profession and its prospects for the future. These range from the apocalyptic - where the future has no need for librarians - to the optimistic vision that sees information professionals at the heart of the "information society" into which we are inevitably heading. In the middle is the more often presented view that library and information professionals have a great future, if only they would come out from behind their issue desks and be more proactive in the services they offer.

I would argue that all these scenarios are too simplistic and fail to acknowledge the range of organisations which utilise and offer information services, as well as the huge differences between those working in the profession. Through personal experience I know there are still some people who wish to work in libraries because they "like books" and want a quiet life. However, the reality of library work, as they soon find out, is very different, requiring a range of social and technical skills. From public and academic libraries to specialist information centres operating in the private sector, technology is changing the way information is produced, distributed and consumed and, more importantly, changing the expectations of users of these information services. Public libraries have responded to these changes with the provision of internet access via the People's Network initiative and the re-branding of some libraries as Ideas Stores, reflecting their role as the provider of services beyond the lending of books.

However, as increasing numbers of households have broadband connections (currently over 60\% according to the latest Ofcom figures) more people choose to buy their books online and public information services can be provided via the internet, how relevant will public libraries be in five years time? Academic libraries are facing similar challenges with students and academics increasingly using the online services provided by the library, rather than actually visiting the building itself. As e-books become more common and digital replaces paper for a range of information services, the physical presence of a library will become less important than the way it integrates these new services into the learning experience of students and working practices of academics. These changes are not restricted to the public sector and impact on anyone providing information services in any type of organisation.

It is this change from a physical and paper-based environment to a more virtual and digital one that presents the greatest threats, as well as opportunities, for library and information professionals. As the building or physical location of a library becomes less important, so does the visibility of those who work in it. The danger of being out of sight and, as a consequence, out of mind, is a real one and may be exacerbated in these times of tighter budgets and credit squeezes. However, in my view, it is this threat that also offers the greatest opportunities for the profession.

As end-users increasingly expect, and are expected, to find their own information rather than relying on librarians to do the job for them, there is an opportunity for many information professionals to redefine their roles and play a more central role in the operations of their employing organisations. I am not just referring to the increasing tendency for information workers to provide training for end-users in the areas of information retrieval, although this is also an opportunity for increasing one's relevance to one's employer. I am thinking more about taking back some of the ground which has been colonised by our colleagues in the computing department. I sense a slowly increasing awareness within some organisations that despite all the large investments in information technology over the previous 20 or so years, there has not been a corresponding increase in productivity. This paradox has been recognised for many years amongst the academic community, which has studied these investments, but it now also seems to be entering the consciousness of managers who have to write the cheques for new computer networks, servers, PCs and the software that they run. Despite all the talk about the transformative power of information technology, the focus has for too long been on the "technology" and not so much the "information". A symptom of this has been the creation of the Chief Information Officer role in many large organisations, but with the vast majority of people filling those roles coming from computing, not information, backgrounds.

\section{Conclusion}

I see a great opportunity for information professionals, who can combine their knowledge of information management with an understanding of the emerging technical infrastructure, to play a more strategic role in the management of their organisations. As digital networks and digital information become ever more central to organisations, both public and private, this opportunity for hybrid roles will become more apparent. We have certainly tried to reflect these changes in our courses at the University of Brighton and look forward to playing a role in the changes yet to come.

Anyone wishing to know more about our teaching at the University of Brighton can visit our blog - www. informationmatters.net - or email the author, Martin De Saulles on mrd@brighton.ac.uk 


\section{Biography}

Dr Martin De Saulles is a Principal Lecturer at the University of Brighton where he teaches and carries out research on information law, knowledge management and online innovation. Prior to joining the University in 2003, Martin worked as an information manager and senior analyst at several management consulting firms in London. Martin was also the founder and managing director of Researcha, an online community for information professionals, which he ran for several years before it was taken over by Freepint.

Dr Martin De Saulles

University of Brighton

Watts Building

Brighton

BN2 4GJ

\section{Who's REALLY Computer Savvy? Web 2.0 Technologies and your Library}

Abstract: What are Web 2.0 applications and which ones will you be implementing in your library? Do "Baby Boomers" fear change and rely too much on email? Are "Gen X-ers/Gen Y-ers" more computer savvy in today's rapidly changing environment? Can social networking technologies enhance our productivity, or are they time-wasters in a professional environment? In this article, based on his paper given at the $39^{\text {th }}$ Annual BIALL Conference held in Dublin in June 2008, Stephen Weiter attempts to answer these questions.

Keywords: social networking; internet; law librarians

\section{Introduction}

For the past few years I have heard presentations and read numerous articles on Web 2.0 technologies and specifically, social networking sites and their applicability to law library services. There seems to be unanimity of opinion that social networking sites and other aspects of what we call "Web 2.0" offer great opportunities for reaching our patrons and for expanding our services. Many of these articles and presentations also attest to the "technological savvy" of younger professionals in our field, and contrast that to the stale, unbending "baby-boomers" who have come to represent the staid institutional "fear of change" group among legal information professionals. The professional literature, blogs, and forums all seem to indicate that "we should all be using these tools but we aren't and we can't figure out why."

Rather than provide an overview and catalog of Web 2.0 social technologies, this article will explore the current adaptations of social networking technologies and their uses. I will also discuss who will (or will not) implement these technologies, and why (or why not), in a professional legal information setting. I will also discuss the supposed generational divide in an effort to uncover attitudes about these technologies and what types of institutions/information centres will likely be early adopters of new technologies, and which types are likely to lag behind. I will also 
Reproduced with permission of the copyright owner. Further reproduction prohibited without permission. 